\title{
Análise do Sistema Toyota em uma indústria de embalagens plásticas da região de Marília - SP
}

\author{
RESUMO
}

\section{Edson Detregiachi Filho} engedson2009@gmail.com Centro Universitário Eurípedes de Marília (UNIVEM), Marília, SP, Brasil

\section{Natália de Oliveira Martins} nataliamartins.om@hotmail.com Centro Universitário Eurípedes de Marília (UNIVEM), Marília, SP, Brasil

\section{Vânia Érica Herrera} vania@univem.edu.br Centro Universitário Eurípedes de Marília (UNIVEM), Marília, SP, Brasil
Os sistemas de produção evoluíram significativamente, passando pelo artesanal, fordista e toyotista. Atualmente muitas empresas utilizam o Sistema Toyota de Produção, que tem como foco principal eliminar todo e qualquer desperdício que não agregam valor à produção para aumentar a produtividade e garantir a qualidade total de seus produtos. Como técnicas e ferramentas desse sistema podem ser citados o Just in Time, que tem a proposta de produzir bens e serviços no momento em que são necessários para atender a necessidade de seus clientes, a Autonomação que visa dar autonomia ao trabalhador sempre que houver necessidade e o Kaizen que tem como foco a melhoria contínua do processo produtivo entre outros. Este trabalho visa analisar a aplicação do Sistema Toyota de Produção em uma indústria de embalagens plásticas da região de Marília-SP, a fim de analisar os impactos positivos e negativos sofridos pela empresa na execução deste sistema. Os métodos de pesquisa utilizados foram pesquisa exploratória, com o levantamento de artigos e autores relevantes da área e leitura do material, e estudo de caso por meio de entrevistas realizadas na empresa em estudo. Esse trabalho obteve como principais resultados a otimização da produção com qualidade, redução de custos, redução de estoques, além da redução de desperdícios através da aplicação de ferramentas do Sistema Toyota de Produção.

PALAVRAS-CHAVE: Sistema Toyota de produção. Indústria de embalagens plásticas. Lean manufacturing. 


\section{INTRODUÇÃO}

Os sistemas de produção evoluíram muito desde o sistema de produção artesanal, passando pelo sistema fordista. $\mathrm{Na}$ atualidade, muitas empresas utilizam-se de técnicas e ferramentas do Sistema Toyota de Produção ou toyotista, onde o foco é o desperdício zero e a produção com qualidade para o atendimento das necessidades dos clientes.

Segundo Dennis (2008), o processo artesanal de fabricação levava meses para ser finalizado e seu custo era alto, porém o cliente tinha a satisfação de manter contato direto com o fabricante e sua equipe. De acordo com o mesmo autor (2008), esse sistema produtivo tinha como características baixo volume de produção e altos preços, máquinas de uso geral que eram utilizadas em quase todos os processos da produção, as organizações eram descentralizadas e a força de trabalho era composta de pessoas semi-independentes com habilidades em diversas áreas. Havia também desvantagens, como por exemplo, somente as pessoas ricas tinham condições de comprar o produto, a qualidade era imprevisível, pois os produtos não seguiam um padrão e a melhoria era vista por alguns como uma ameaça e por isso não era amplamente compartilhada.

No final do século XIX, Henry Ford introduziu seus conceitos de produção. As novas implantações permitiram a redução na quantidade de esforço humano exigido na montagem de um produto: aumentar a produtividade e diminuir os custos proporcionais ao volume produzido (WOOD JÚNIOR, 1992, p. 9).

Henry Ford queria um carro fácil de fabricar e fácil de consertar. Isso foi possível devido à produção em massa de Taylor que possibilitou o intercâmbio de peças e a facilidade na montagem e deu origem ao Model T, de 1908. Além disso, seguindo a idéia deTaylor, ele diminuiu o número de ações de cada trabalhador da linha de montagem criando a linha de montagem em movimento, que levava o carro até o trabalhador parado e possibilitava uma instabilidade produtiva, já que o trabalhador mais lento passou a ser mais rápido e o trabalhador rápido passou a diminuir a velocidade de executar seu trabalho (DENNIS, 2008).

O Sistema Toyota de Produção surgiu no Japão no início de 1960, por meio de Eiji Toyoda e Taiichi Ohno. O Japão vivenciava um período de crescimento econômico excepcional entre 1959 e 1960 e a produção em massa ainda era muito utilizada. Dessa forma, o objetivo da Toyota era pensar em um sistema japonês que fosse capaz de superar o estilo americano de produzir. Logo, o principal foco do Sistema Toyota de Produção era aumentar a variedade de modelos produzindoos em pequenas quantidades (OHNO, 1997).

O consumidor atual demonstra grande interesse em qualidade de produtos e serviços, bem como outros requisitos como pontualidade de entrega. O Sistema Toyota de Produção, como um conjunto de técnicas e ferramentas que tem como foco a qualidade total, a eliminação de desperdícios entre outros, vem ao encontro do atendimento das necessidades dos clientes.

Desta forma, prioriza o contexto atual, otimizando o processo produtivo para que se obtenha um produto de boa qualidade e, ao mesmo tempo, garantindo que seu custo seja cada vez mais baixo. 
O objetivo desse trabalho é analisar a aplicação do Sistema Toyota de Produção em uma indústria de embalagens plásticas da região de Marília-SP, a fim de verificar os impactos positivos e negativos experimentados pela empresa na implantação e execução deste sistema. A metodologia utilizada foi a da pesquisa exploratória, com o levantamento de artigos e autores relevantes da área e estudo de caso por meio de entrevistas realizadas na empresa foco do estudo. A implantação desse sistema em uma indústria de embalagens plásticas da região de Marília tem como principal princípio desperdício zero e melhoria contínua. Assim, tal estudo justifica-se pelo fato de analisar se os objetivos da implantação foram alcançados, assim como as principais dificuldades enfrentadas.

\section{REFERENCIAL TEÓRICO}

Os sistemas produtivos evoluíram de forma significativa com o passar dos anos. No século XIX o sistema de produção era o artesanal, no qual cada produto era fabricado conforme as especificações e o gosto do cliente. O produto era único, fabricado em máquinas de uso geral, em organizações descentralizadas, seu volume de produção era baixo e o seu custo era alto. Havia desvantagens neste sistema como, por exemplo, a qualidade ser imprescindível, as melhorias eram vistas como ameaças e somente os ricos poderem comprar estes produtos (DENNIS, 2008, p.20).

Para Paranhos Filho (2007), ressalta-se a importância de não confundir produção artesanal com simplicidade, já que um produto artesanal pode ser muito complexo, realizado por um grupo de artesãos com objetivo final de produzir um objeto determinado. Os automóveis eram produzidos artesanalmente de forma surpreendente onde o ajuste de cada componente, que era fabricado isoladamente sem padrões fixos de medida, era realizado pelos artesãos de duas em duas peças até que o encaixe do veículo fosse completo.

No final do século XIX, Henry Ford introduziu seus conceitos de produção. Ford inovou a produção em massa de Fred Winslow Taylor, propondo a intercambiabilidade e facilidade na montagem de peças, padronizando o uso de peças em suas operações. Ford também reduziu as ações exigidas de cada trabalhador e criou a linha de montagem em movimento, onde o carro que estava sendo fabricado era levado até o trabalhador que permanecia parado. Dessa forma, Ford conseguiu reduzir a quantidade de esforço humano na montagem de um automóvel, dobrar o salário dos trabalhadores e reduzir custos, resultando na diminuição de preço dos veículos. A produção em massa é caracterizada por tempo de ciclo reduzido, estudo de tempo e movimento, medição e análise para melhorar o processo de forma contínua e trabalho padronizado. Métodos ainda utilizados nas empresas (DENNIS, 2008).

Dennis (2008) acredita que os princípios de Taylor eram baseados entre planejamento e produção onde era determinada a melhor forma de fazer o trabalho com ciclos rápidos e de repetição. A produção em massa é sinônimo de trabalho bruto desumanizador, porém não era essa a intenção de Taylor, ele buscava trabalho padronizado, tempo de ciclo reduzido e análise para melhoramento contínuo do processo. 
Wood Júnior (1992) afirma que Ford também reduziu drasticamente o tempo de preparação das máquinas fazendo com que as mesmas executassem uma tarefa por vez. Por outro lado, havia falta de flexibilidade já que o trabalhador da linha de montagem tinha apenas uma tarefa. No entanto ele não comandava componentes, não preparava ou fazia a manutenção de equipamentos, não inspecionava a qualidade e nem mesmo entendia a tarefa que seu vizinho executava.

A produção em massa pode ser separada em duas fases, sendo sistema fixo e sistema móvel. No sistema fixo o veículo se mantinha parado para ser fabricado, onde os trabalhadores se movimentavam transportando as peças necessárias para a montagem do mesmo. Já no sistema móvel, o chassi do carro se movia e passava pelos operadores, que se mantinham parados em seus postos de trabalho, e adicionavam os componentes necessários ao veículo (ARAUJO, 2009, p. 39).

A Ford procurou verticalizar-se totalmente, passando a produzir todos os componentes dentro de sua própria empresa, isso se deu devido aos fornecedores não conseguirem atender a demanda de peças com tolerâncias mais estreitas e prazos de entrega menores. Tal atitude possibilitou que Ford produzisse em massa praticamente tudo o que necessitava. Em contrapartida, ele não conseguia gerenciar globalmente a empresa sem deixar de centralizar todas as decisões. Essa é uma das razões do declínio da empresa nos anos 30. Outro motivo foi que Alfred Sloan, da General Motors, divisionalizou a empresa e criou uma linha com cinco modelos de veículos para atender melhor o mercado. Durante décadas, o sistema de produção criado por Ford e aperfeiçoado por Sloan funcionou perfeitamente, permitindo com que as empresas americanas dominassem o mercado automotivo (WOOD JÚNIOR, 1992).

Após a Segunda Guerra Mundial, os japoneses tinham como objetivo diminuir custos e produzir pequenas quantidades de muitos modelos de carros, simultaneamente. O presidente da Toyota, Toyoda Kiichirõ, dizia que deveriam alcançar os Estados Unidos em três anos para que a indústria automobilística japonesa sobrevivesse. Isso significa que o trabalho aumentaria e a mão de obra diminuiria, onde surgiria um novo começo para a Toyota. A ideia que marcou o início do sistema produtivo atual da Toyota foi eliminar o desperdício para que a produtividade pudesse aumentar. Eles queriam um sistema produtivo que pudesse superar o sistema de produção em massa convencional (OHNO, 1997).

O Sistema Toyota de Produção deu à Toyota Motors Corporation a oportunidade de fabricar carros de grande qualidade e confiabilidade com baixo custo de produção, trouxe agilidade em produzir para atender a demanda e proporcionou o controle de estoque de peças, matéria-prima e produtos acabados, deixando-os baixos (OSONO et al., 2008).

Para Womack, Jones e Roos (2004), o sistema da produção enxuta se mostra superior ao sistema de produção em massa em produtividade, qualidade e eficiência, pois requer menos recursos a serem utilizados como estoque e esforço físico humano, por exemplo. Atende os diversos gostos dos consumidores oferecendo maior variabilidade de produtos, combinando o melhor da produção artesanal com o melhor da produção em massa, aproveita a capacidade intelectual humana e é capaz de se adequar no desenvolvimento de novas tecnologias e na crescente internacionalização da economia. 
A produção enxuta é a metodologia de administração mais significativa dos últimos 50 anos. Consiste em eliminar o máximo de perdas possíveis, excesso de estoque e etapas de processos que não agregarem valor ao produto (JACOBS e CHASE, 2009).

Para Shingo (1996) existem operações que agregam e que não agregam valor ao produto. Operações que não agregam valor podem ser conceituadas como perdas. Assim, melhorias nas atividades produtivas sempre serão necessárias. Operações que agregam valor compõem os processamentos do produto, que modificam a matéria prima, mudando a forma e a qualidade do mesmo. Quanto mais valor agregado nas operações, maior a eficiência das mesmas.

Os pilares necessários à sustentação desse sistema são o Just in Time e a Autonomação. Para Ohno (1997), Just in Time (JIT) significa trabalhar com a produção puxada onde as peças utilizadas na montagem atendam à linha de produção no momento em que são necessárias e na quantidade necessária a fim de chegar ao estoque zero.

Produção puxada se refere a um processo inicial que deve produzir um bem ou serviço assim que o cliente de um processo posterior o solicite (WOMACK e JONES, 1998).

Slack, Chambers e Johnston (2009) afirmam que o Just in Time busca atender a demanda imediatamente, com excelente qualidade e sem desperdícios. Autonomação, ou Jidoka, surgiu da criação de uma máquina de tecer autoativada criada por SakichiToyoda, criador da Toyota Motor Company, onde produtos com defeitos não eram produzidos já que a máquina parava imediatamente se algum dos fios verticais ou laterais do tecido se rompesse ou saíssem do lugar.

Uma máquina automatizada com um toque humano (autonomação) é aquela que está ligada a um dispositivo de parada automática, dessa forma, autonomação significa transmitir inteligência humana para uma máquina (OHNO, 1997).

Segundo Monden (2015) JIT significa produzir as unidades necessárias, na quantidade necessária e no tempo necessário. Já a Jidoka pode ser definida como o controle autônomo de defeitos que dá apoio ao JIT para evitar que processos defeituosos prejudiquem os processos subsequentes.

Ohno (1997) acredita que reduzir custos deve ser o objetivo das indústrias manufatureiras que procuram sobreviver no mercado atual. Para isso, é necessário ter um sistema de gestão total, que seja capaz de melhorar a habilidade e capacidade humana a fim de amplificar a criatividade e a produtividade na utilização de máquinas, instalações e eliminação de desperdício.

Ao pensar em eliminação de desperdício deve-se observar a eficiência do sistema de produção já que o aumento da eficiência está associado à redução de custos. O verdadeiro avanço da eficiência surge quando se produz zero desperdício e aumenta-se a porcentagem de trabalho a $100 \%$. De maneira que, no Sistema Toyota de Produção, deve-se produzir apenas o necessário e diminuir a força de trabalho a fim de reduzir o excesso da capacidade e de condizer à quantidade necessária (OHNO, 1997). 
A Toyota identificou sete tipos de desperdícios que constituem a base da filosofia enxuta, os quais acreditam serem utilizados em diversos tipos de operações distintas de serviços e de produção (SLACK, JOHNSTON e CHAMBERS, 2009).

O desperdício da superprodução pode ser considerado como um dos maiores fatores de perda para uma instituição. A superprodução pode acontecer de forma quantitativa, caracterizada pelo excedente de produtos de um lote de produção onde se produz mais do que o cliente necessita e o excedente acaba se tornando estoque e, de forma antecipada, caracterizada pela produção do produto antes de ser solicitado, ou seja, preparar o material antes da data de expedição, causa impactos para a organização como o adiantamento do consumo de matéria prima, energia, equipamentos e armazenamento (JUNIOR, 2008).

O tempo de espera consiste no colaborador parado precisando esperar uma próxima etapa do processo, ferramentas, peça, suprimento ou, até mesmo, não ter tarefas a serem realizadas por falta de estoques, atrasos de processos, interrupção de equipamento e gargalos de capacidade (LIKER e MEIER, 2007).

Outro desperdício é o transporte que pode ser causado pelo layout inapto do local de trabalho devido ao grande tamanho dos equipamentos ou pela produção de grandes lotes que dificultam seu transporte de um processo para outro. Também pode ser definida como o transporte de peças durante o processo produtivo, atividade que não agrega valor ao produto, porém necessária já que materiais precisam ser movidos dentro do ambiente fabril, mas isso deve ser reduzido (DENNIS, 2008).

O desperdício da superprodução é composto por atividades que podem ser dispensadas no processamento das peças a serem produzidas, causando perdas quando são fabricados produtos com qualidade acima do necessário (ROMEIRO FILHO et al., 2011).

O excesso de estoque pode causar lead time maior, obsolescência, produtos com defeitos, atrasos e custos com transporte e armazenagem devido ao excesso de matéria prima armazenada, estoque em processo ou produtos finalizados. Também oculta problemas como instabilidade na produção, paralisação de equipamentos e longos setups (LIKER e MEIER, 2007).

A movimentação está associada aos colaboradores, que podem parecer estar ocupados, porém, às vezes, não há valor agregado ao trabalho realizado. Por isso, a simplificação das tarefas diárias é uma excelente fonte de redução deste desperdício (SLACK, JOHNSTON e CHAMBERS, 2009).

Por último, a muda de correção também caracterizada por produtos defeituosos está relacionada à fabricação de produtos e o conserto dos mesmos. Esse retrabalho envolve todo o material, o tempo e a energia gastos na produção deste produto (DENNIS, 2008).

A Toyota criou um mapa da cadeia de valor que divide as ações necessárias para projetar, pedir e produzir um produto em três categorias. A primeira categoria é das ações que realmente criam valor ao produto, de acordo com os clientes. $\mathrm{Na}$ segunda categoria estão ações que não criam valor, porém são necessárias para a fabricação do produto, denominadas de muda Tipo Um. A terceira categoria engloba as ações que não criam valor ao produto segundo os clientes, 
denominadas de muda Tipo Dois. Esta terceira categoria deve ser eliminada (WOMACK e JONES, 1998).

O sistema da produção enxuta é composto por ferramentas utilizadas para impulsionar e garantir os resultados almejados deste sistema produtivo. Uma das principais ferramentas é o Sistema Kanban.

Para Monden (2015, p.9):

Neste sistema, o tipo e a quantidade de unidades necessárias são escritos num cartão similar a uma etiqueta, chamado Kanban, que é enviado pelos trabalhadores em um dos processos para os trabalhadores no processo procedente. Como resultado, muitos processos numa planta ficam conectados uns aos outros. Essa conexão de processos numa fábrica permite que haja um controle melhor das quantidades necessárias para vários produtos.

O Kanban surgiu da ideia de supermercado com a ideia de imaginar o processo inicial de uma linha produtiva como um tipo de loja onde o processo final (cliente), vai até o processo inicial (supermercado) para obter as peças necessárias no momento e quantidade necessários, assim, o processo inicial rapidamente produz a quantidade retirada (reabastecimento das prateleiras. Normalmente o Kanban é um pedaço de papel que transporta informações verticais e laterais na Toyota e entre a Toyota e empresas colaboradoras. Estas informações podem ser separadas em três classes: informações de coleta, de transferência e de produção. No Sistema Toyota de Produção, o Sistema Kanban impede a superprodução, não havendo necessidade de estoques extras (OHNO, 1997).

Já, o Sistema 5 S é classificado em Separar (Seiri), Classificar (Seiton), Limpar (Seiso), Padronizar (Seiketsu) e Manter (Shitsuke). Assim, com base em Dennis (2008) apresenta-se a seguir uma descrição acerca de cada componente do sistema S.

Seiri consiste em definir o que se precisa para obter os objetivos de produção separando do que não precisa. Deve ser feita a etiquetagem vermelha nos itens desnecessários, que os destina para a remoção dos mesmos.

O Seiton tem como base promover a organização dos ítens que não foram descartados, de forma a evitar movimentos desnecessários. Para obter uma boa organização, a empresa deve utilizar sistemas visuais para facilitar a localização dos objetos, como o uso de quadros na parede para fixar os materiais de uso frequente, fixar as posições dos equipamentos e de prateleiras com fita adesiva, utilizar cores para diferentes significados e para uma boa identificação e identificar áreas perigosas e por onde as pessoas podem caminhar. Um sistema visual é um conjunto de dispositivos visuais utilizados para compartilhar informações com uma só olhada. Um ambiente organizado deve ser aquele que qualquer pessoa possa encontrar qualquer coisa a qualquer momento e onde situações fora do padrão sejam evidentes para todos.

No Seiso define-se o que e como limpar, quem irá limpar e o que significa limpo para a equipe. Os métodos de limpeza devem ser definidos e os materiais necessários devem estar disponíveis. As responsabilidades e os horários de limpeza devem ser colocados de forma visível. Os membros da equipe devem ser treinados para inspecionar a regularidade de equipamentos e ambientes. 
O Seiketsu consiste em uniformizar as tarefas diárias. Um trabalho padronizado evidencia as condições fora do padrão e devem ser claros, simples e visuais. Um quadro de ferramentas padronizado pode identificar, por exemplo, quais as ferramentas que estão faltando naquele momento.

Finalmente, o Shitsuke consiste na continuação das práticas do Sistema 5S. Este sistema deve ser adotado pelos membros de equipes para que o mesmo crie raízes na empresa.

O 5 S pode ser entendido como uma forma descomplicada de arrumar a casa para organizar ambientes de trabalho que destacam a ordem visual, a organização padronização e limpeza, ajudando a eliminar todos os tipos de desperdícios como as incertezas, as buscas por informações significativas, a espera e outros. Tornando tudo claro, previsível e eliminando o desnecessário a desordem é reduzida, os objetos necessários estão sempre nos mesmos lugares e o trabalho é mais rápido e facilitado (SLACK, CHAMBERS E JOHSNTON, 2009).

Para Dennis (2008), o trabalho padronizado traz benefícios para a empresa como, por exemplo, a estabilidade de processos, pontos de início e parada preciso para cada processo, aprendizagem organizacional, soluções de auditorias e de problemas, permitindo analisar a situação atual do processo e apontar problemas, envolvimento dos funcionários para padronizar processos e uso de poka-yoke para identificar problemas, treinamentos de funcionários e kaizen.

O trabalho padronizado tem como objetivo o Kaizen. Para que a empresa progrida o trabalho padronizado deve se alterar (DENNIS, 2008).

O Kaizen é definido como melhoramento contínuo. As melhorias contínuas, mesmo pequenas, são de extrema importância para as empresas e devem ocorrer de forma sucessiva para que, a cada determinado espaço de tempo, alguma melhoria seja efetuada (SLACK, CHAMBERS E JOHSNTON, 2009).

Um programa Kaizen bem planejado é fracionado em três segmentos: orientado para a administração, orientado para o grupo e orientado para a pessoa. O segmento orientado para a administração exige dos envolvidos aplicação de métodos estatísticos e de controle, novas técnicas de gestão e resolução de problemas a fim de determinar ações de aperfeiçoamento das questões estratégicas da empresa e melhorias de desenvolvimento de processos e projetos. No segmento orientado para o grupo, o objetivo é desenvolver métodos, análises e processos de resolução de problemas na empresa, identificando sempre sua causa raiz e implantando as soluções encontradas envolvendo ferramentas de gestão e análise da qualidade e atentando para as necessidades de melhoria. Já o segmento orientado para a pessoa, propõe desencadear ações de melhorias para os colaboradores da organização, objetivando a satisfação do mesmo em relação ao seu local de trabalho, segurança pessoal e tudo aquilo que possa auxiliar para o conforto, confiança e melhor desempenho dos funcionários na organização (JUNIOR, 2008).

Já o Controle visual ou Andon, é um quadro indicador de parada de linha, pendurado acima da linha de produção que, por meio de uma luz, aponta problemas no processo. Esta luz é verde quando as operações estão normais, amarela quando um operador requer ajuda e vermelha se uma parada de linha for necessária. Os operadores de máquinas não devem ter receio de parar a linha para que as anormalidades sejam eliminadas completamente (OHNO, 1997). 
Ohno (1997) define Poka-yoke em um dispositivo à prova de defeitos que possibilita garantir a qualidade dos produtos $100 \%$ do tempo. Quando algum passo é esquecido, o processo seguinte não será iniciado, por exemplo.

Para Werkema (2012), o Poka-yoke é um termo japonês que significa à prova de erros que consiste em um conjunto de procedimentos ou dispositivos que tem como propósito localizar erros e corrigi-los antes que se tornem defeitos percebidos pelos consumidores finais. Para que um erro não se torne defeito, deve-se tomar as devidas ações para corrigi-lo no momento em que são detectados. Erros como a montagem, incorreta de componentes e o esquecimento de uma peça em um procedimento de montagem são exemplos de falhas que o dispositivo Poka-yoke pode evitar.

Cabe destacar uma ferramenta importante que é o Mapeamento do Fluxo de Valor (MFV), pois este auxilia no entendimento do processo atual e a identificar possíveis melhorias. Esta ferramenta consiste em um mapeamento do processo produtivo na linguagem de símbolos a fim de enxergar a combinação de processos necessários para garantir que produtos ou serviços cheguem aos consumidores finais (DENNIS, 2008).

Manutenção é uma função indispensável nas atividades de produção, é a forma que as organizações tentam impedir as falhas cuidando de suas instalações físicas. Estas atividades são responsáveis por um tempo significativo da atenção da gerência de produção e trazem benefícios para a empresa como, por exemplo, maior segurança, confiabilidade, qualidade e menores custos de operações. As tarefas de manutenção combinam três abordagens para cuidar de suas instalações físicas. A manutenção corretiva consiste em permitir que as instalações operem até quebrarem, ou seja, só é realizada a manutenção depois de a falha ter acontecido. A manutenção preventiva objetiva reduzir ou eliminar as chances de falhas através da manutenção das instalações em intervalos de tempo prédeterminados, por exemplo, realizar a limpeza e a lubrificação das máquinas. A manutenção preditiva propõe executar manutenção apenas quando as instalações precisarem dela (SLACK, JOHNSTON e CHAMBERS, 2009).

Segundo Dennis (2008), a Manutenção Produtiva Total (TPM) proporciona um trabalho de manutenção básica (inspeção, limpeza, ajustes) aos integrantes da equipe de trabalho que, consequentemente, praticam a manutenção preventiva, vistorias e melhorias de equipamentos e de atividades de alto valor. Para obter eficiência das máquinas se deve eliminar as seis grandes perdas, que são tempo de parada, atrasos na montagem e nos ajustes, perdas de velocidade ou perdas ocultas, velocidade reduzida, defeitos de processamentos e rendimento reduzido.

A Manutenção Produtiva Total busca cinco metas para um bom desenvolvimento de manutenção da produção. São elas: melhorar a eficácia dos equipamentos ao observar as perdas, realizar manutenção autônoma permitindo a responsabilidade de algumas tarefas de manutenção aos operadores, planejar a manutenção, treinar os colaboradores em habilidades pertinentes para a manutenção e conseguir conduzir os equipamentos com a utilização da manutenção preventiva (SLACK, JOHNSTON e CHAMBERS, 2009). 
Uma técnica para localizar problemas, desenvolvida pelo Sistema Toyota, foi o 5W que significa Cinco Por quês. Perguntando cinco vezes por que, sempre que se encontrar um problema, e respondendo a cada vez, pode-se ajudar a descobrir a origem do problema e corrigi-lo. A solução é denominada "como" $(1 \mathrm{H})$, dessa forma, cinco por quês é igual a um como fazer. (OHNO, 1997)

Outra definição importante dentro do Sistema Toyota é a de tempo de set-up que é determinado como o tempo decorrido na troca do processo de uma atividade para a outra. A redução desde tempo pode ser alcançada por meio de procedimentos como eliminar o tempo necessário para busca de determinada ferramenta ou equipamento. Outra abordagem do tempo de set-up é tornar o trabalho executado enquanto a máquina está parada para ser executado enquanto a mesma estiver operando (SLACK, JOHNSTON e CHAMBERS, 2009).

De acordo com Monden (2015, p.15-16):

Um Takt Time, ou um tempo de ciclo, é o número padrão especificado de minutos e segundos dentro dos quais cada linha precisa fabricar um produto ou uma parte. O rendimento necessário por mês é predeterminado pela demanda do mercado.

No Sistema Toyota de Produção, as trocas de ferramentas são realizadas de forma rápida e aperfeiçoadas com a prática. Nos anos 40 tinha duração de duas a três horas, nos anos de 1950 esse tempo foi diminuído de uma hora para quinze minutos e, nos dias atuais, as trocas foram para três minutos apenas (OHNO, 1997).

Ohno associou a troca rápida de ferramentas com a produção de lotes menores, o que resultou em economia de custos. Além disso, os lotes menores possibilitam qualidade dos produtos já que as falhas ficam evidentes e fáceis de serem detectadas, e lead time menor devido ao menor número de produtos processados (DENNIS, 2008).

Shingo (1996) acredita que a troca de ferramenta em um único toque é a forma mais eficiente para melhorar o setup de uma linha de produção. Este setup pode ser realizado de duas maneiras, sendo a primeira o setup interno onde se podem realizar as operações de setup somente com a máquina parada como a troca de matrizes, e o setup externo que consiste nas operações de setup que devem ser finalizadas enquanto a máquina estiver trabalhando como, por exemplo, o transporte de matrizes para o armazenamento da mesma.

Segundo Muniz (2012) apud Corrêa e Corrêa (2007), a filosofia Lean Manufacturing se baseia no Sistema Toyota de Produção com foco na qualidade dos produtos e serviços, na redução de desperdícios e na flexibilidade produtiva.

Rodrigues (2014) afirma que a relação do Sistema Toyota com o Lean Manufacturing está nas novas contribuições que surgiram, unindo novos conhecimentos e princípios ao modelo de origem com novas formas de gerenciar a produção e implantação de novos métodos.

O Planejamento HoshinKanri também conhecido como gerenciamento pelas diretrizes ou ainda como desdobramento das diretrizes, teve início devido à necessidade de um sistema administrativo mais flexível com tempo reduzido de retorno das variações internas e externas à empresa. É um sistema que ajuda na determinação dos objetivos da empresa através de planejamento estratégico. Tem origem no controle estatístico da qualidade considerado um dos pilares da Gestão 
da Qualidade Total - TQM (Total Quality Management). Dessa forma, é utilizado para o controle de qualidade em todos os setores da organização e para o melhoramento contínuo das atividades desdobrando diretrizes em todos os níveis hierárquicos da empresa permitindo o alinhamento dos objetivos estratégicos para todos os setores. O desdobramento estratégico consiste na disseminação de procedimentos e orientações pela empresa através do processo de cascata, onde os diretores absorvem as diretrizes e repassam para seus colaboradores de uma forma mais explicativa (GUELBERT, 2012).

Neto (2007) acredita que o planejamento HoshinKanri tem como foco os problemas de altos níveis, objetivando cumprir as metas que não podem ser alcançadas pelo Planejamento de Rotina garantindo o funcionamento do planejamento estratégico definido pela organização. Assim, deve-se haver um contínuo processo de controle de verificação para se certificar se o que está sendo realizado é compatível com os objetivos definidos pela empresa e com o caminho que a mesma deseja seguir.

Para Dennis (2008), um planejamento estratégico com eficiência deve responder questões importantes como aonde a empresa está, para onde ela quer ir, como irá chegar ao objetivo definido e quais obstáculos estarão no meio do percurso.

O planejamento Hoshin utiliza o método PDCA como uma de suas ferramentas a fim de identificar as mudanças de melhorias necessárias à organização, se tornando a maneira mais prática de operacionalizar os procedimentos da empresa (NETO, 2007).

O planejamento Hoshin é um sistema guia e de resultados que indica aonde cada ferramenta Lean deve ser utilizada conforme as necessidades da organização. Por meio do planejamento Hoshin se busca identificar as iniciativas de melhorias, desenvolver estratégias para cada uma delas com a utilização da ferramenta Pensamento $A 3$, espalhar as estratégias $A 3$ definidas em toda empresa e abranger todos os membros de equipes na resolução dos problemas (DENNIS, 2008).

Para Dennis (2008), o Ciclo PDCA é atividade fundamental da gerência que tem por significado Planning (Planejando), Do (Fazer), Check (Verificar) e Act (Agir). Foi inserido por Deming aos japoneses em 1954 em uma palestra na Associação Japonesa de Cientistas e Engenheiros. Tem como base o GTS (GraspingtheSituation) que significa em português Agarrar a Situação e serve de base para os estágios do PDCA criando uma consciência do problema por meio da percepção de pontos importante como, por exemplo, o que realmente está acontecendo e o que deveria estar acontecendo. Apresenta-se a seguir uma definição dos estágios do PDCA segundo o autor.

Planejando consiste em definir para onde a empresa quer ir e como fazer para chegar lá utilizando elementos como o Cinco Ws e Um H e um plano de medição.

Fazer consiste em ter um bom piloto para que seja possível reforçar e confirmar o plano antes de sua implementação.

Verificar também quer dizer confirmar através de medições estáveis que irão facilitar a verificação tornando os problemas evidentes. 
Agir consiste em refletir sobre a situação atual da empresa após verificar e tomar a devidas ações, incluindo a padronização de um produto final e contramedidas quando os resultados do processo são abaixo do esperado.

Segundo Fusco e Sacomano (2007), o Ciclo PDCA é uma ferramenta importante que deve ser utilizada a fim de buscar uma melhoria contínua. Deve ser executado durante todo o processo de fabricação acompanhando a produção.

O Relatório A3, também conhecido como Pensamento A3, tem como objetivo elaborar em uma única página uma relação da solução de um problema, que contenha o resumo do problema, sua causa raiz e as ações adotadas para corrigiIo (LIKER e CONVIS, 2013).

Trata-se de um relato em uma página de folha A3, com $27 \times 42$ centímetros de dimensão, criado pela Toyota para resumir as atividades de melhoramento contínuo Kaizen. O Pensamento A3 se tornou uma ferramenta de comunicação eficaz para as organizações, que pode ser utilizado de quatro formas. A primeira é o A3 de planejamento Hoshin onde é relatado os Hoshins de setores e da empresa como um todo; a segunda maneira é o A3 para solução de problemas onde consta o resumo dos problemas e suas contramedidas e, em seguida, tem-se o A3 de propostas com a finalidade de apresentar novas ideias. Por último, o A3 da situação atual para relatar os problemas e o Hoshin atual da empresa (DENNIS, 2008).

Para Liker e Convis (2013), os relatórios A3 compõem a gestão visual de uma organização, que é de suma importância para a Toyota. Os relatórios são fixados em painéis de fácil visualização seguindo padrões que permitem o seu entendimento imediato.

Segundo Werkema (2012), o uso da gestão visual proporciona benefícios para a empresa como, por exemplo, a melhoria na comunicação entre departamentos e turnos de trabalho, respostas rápidas na ocorrência de falhas, melhoria do entendimento sobre o funcionamento produtivo da empresa, visualização direta da conquista de metas estabelecidas, aumento da compreensão da eliminação de desperdícios, melhora na capacidade de estabelecer tarefas prioritárias, e a visualização dos procedimentos operacionais padrões adotados pela organização.

A gestão visual é de extrema importância para a Toyota. Toda métrica significativa para a empresa é exposta, principalmente na linha de produção, para que todos os que estão comprometidos em alcançar os objetivos definidos pela organização possam vê-la. Muitas das ferramentas do Sistema Toyota de Produção têm como propósito evidenciar os padrões a serem seguidos visualmente, para que qualquer falha seja percebida. Para a Toyota não existem problemas sem padrões, pois os problemas são os espaços entre os padrões e a realidade (LIKER e CONVIS, 2013).

O Kaikaku surgiu no período em que o Japão passava por uma crise financeira onde a Toyota precisava de alterações drásticas em seus processos produtivos. Portanto, Kaikaku consiste em uma filosofia japonesa utilizada para executar mudança radical ou uma melhoria em um curto intervalo de tempo em determinada atividade, processo ou produto (SOUZA, 2015).

Womack e Jones (1998, p. 365) definem Kaikaku como: 
"Melhoria radical de uma atividade a fim de eliminar desperdícios, por exemplo, reorganizando as operações de processamento para um produto de modo que, em vez de viajar de e para "ilhas de processo", o produto proceda pelas operações em um fluxo contínuo e em um curto espaço de tempo. Chamado também de Kaizen revolucionário, Kaizen do fluxo e Kaizen do sistema."

A Gestão Diária é importante para direcionar a atenção dos colaboradores aos objetivos Hoshin da empresa com base na revisão do desempenho do dia anterior e em reuniões diárias para discussão dos objetivos relacionados com o objetivo decorrente do dia. A Gestão Diária é auxiliada por ferramentas visuais como diagramas, gráficos e informações codificadas por cores que demonstram, por exemplo, o desempenho em cada grupo de trabalho de acordo com as métricas anteriormente definidas pela empresa, ou seja, mostram todo o status em relação a uma meta (LIKER e CONVIS, 2013).

Finalmente, a cultura japonesa tem grande influência no Sistema Toyota de Produção, afinal a cultura da Toyota evoluiu dentro da cultura japonesa. Os japoneses são disciplinados, atentos aos detalhes, trabalham em grupo, se dedicam à empresa, buscam a perfeição, permanecem no emprego a vida toda. Essas e outras características apoiam o Modelo Toyota. A Toyota percebeu que para transmitir seu sistema para outros países, deveria permitir que a cultura Toyota se adaptasse à cultura local. A nova cultura só seria transmitida através de pessoas que vivenciaram e participaram da mudança cultural enxuta, uma vez que - Sistema Toyota de Produção sempre teve a ver com a aprendizagem na prática (LIKER e MEIER, 2007).

Segundo Liker e Convis (2013), precisam acontecer mudanças de cultura para que deixe de ser aquela que limitam as pessoas em suas atividades diárias para que seus resultados pareçam bons e passe a ser aquela em que as pessoas direcionam seu foco no cliente e na melhoria contínua. Porém, mudar de cultura não é fácil, sua evolução é lenta e para transformá-la é preciso muito tempo e paciência.

São necessários cerca de três anos ou mais para que a cultura enxuta seja desenvolvida, onde os colaboradores da empresa compreendam o fluxo, enxerguem as perdas se sintam aptos a eliminá-las e desenvolvam a disciplina para que as mudanças sejam mantidas (LIKER e MEIER, 2007).

\section{RESULTADOS}

O estudo de caso foco desse trabalho foi realizado em uma indústria de embalagens plásticas da região de Marília- SP com o objetivo principal de analisar as dificuldades de implantação do sistema Lean de produção bem como os benefícios obtidos por essa implantação.

Em entrevista realizada com o Diretor da empresa estudada, apurou-se que o sistema Lean foi implantado devido a demandas da organização como, por exemplo, a necessidade de atender aos clientes de forma mais rápida, reduzir estoques e desperdícios, produzir lotes menores e diminuir custos. De acordo com estas e outras necessidades, o sistema Lean foi o sistema que mais se adequou à empresa. 
A expectativa com a implantação de um novo sistema era a de reduzir estoques e lead time, adquirir uma produção enxuta que fosse mais barata e mais simples de se administrar. Porém o sistema leva tempo para que seja plenamente implantado, cerca de cinco anos para obter bons resultados. A empresa em estudo está no seu terceiro ano de implantação e já é possível observar melhoras nos processos produtivos da mesma. O que dificulta o rápido andamento da implantação da nova sistemática de produção é a dificuldade dos funcionários de aderirem à essa nova metodologia.

Segundo o Diretor da empresa, durante o processo de implantação, a mudança de cultura dos funcionários, os problemas por excesso de manutenção, pessoas demais em lugares errados e a dificuldade em exporem suas dificuldades, foram os problemas apontados como os mais frequentesna organização. Nessa etapa, ainda observa-se como, por exemplo, a insatisfatória disponibilidade de equipamentos, a dificuldade de manutenção do $5 S$, o trabalho nem sempre padronizado e a baixa capacitação de funcionários.

As principais técnicas e ferramentas que foram e estão sendo implantadas pela empresa são o 5S, as atividades Kaikaku realizadas na organização, a troca rápida de ferramenta (TRF), o método de solução de problemas $A 3$, o HoshinKanri definido pela empresa, o mapeamento do fluxo de valor, padronização de trabalho e gerenciamento diário. Dessas ferramentas, as que trouxeram maior resultado foram o HoshinKanri, o gerenciamento diário e o método de solução de problemas A3.

Para o Diretor da empresa, o sistema Lean de produção possibilitou uma melhoria de indicadores como o de lead time, que anteriormente era de 60 dias e atualmente é de 20 dias. 0 estoque passou de meses para cerca de 7 a 8 dias, o setup que era de 5 horas hoje é de 70 minutos. A implantação do novo sistema tornou os indicadores da empresa mais precisos.

Houve a necessidade de investimentos para a implantação, principalmente em mão de obra. Durante o processo de implantação, o quadro de funcionários foi trocado algumas vezes devido a dificuldade das pessoas de se adaptar a mudanças e a uma nova forma de trabalhar. Essas trocas de funcionários tiveram investimento bastante alto para a empresa. Houve investimentos em maquinários também, para que os mesmos pudessem atender a produção de lotes pequenos.

Para que o sistema Lean fosse implantado por esta indústria de embalagens plásticas foi necessário investir na contratação de uma consultoria especializada no sistema para que os consultores direcionassem a empresa para a implantação do mesmo. Atualmente, a empresa caminha sozinha e faz contratações de workshops para capacitação constante dos funcionários.

O Diretor da organização está bastante satisfeito com o sistema Lean, que hoje faz parte do sistema de gestão interno da empresa. Porém sabe que ainda tem muito para ser realizado e está trabalhando para que os objetivos da empresa sejam alcançados.

Na visão do Diretor, os impactos causados pela implantação do sistema junto aos colaboradores, foram de que os mesmos passaram a perceber que tudo pode e deve ser melhorado e que isso depende de cada um, e que todos os problemas que ocorrerem vão ser evidenciados pelo sistema implantado. Com relação aos fornecedores, passaram a perceber que a empresa está comprando menos em 
mais vezes. Já quanto aos clientes, a empresa está fazendo um trabalho de conscientização de compras efetuadas semanalmente através de negociações.

Dentre as entrevistas realizadas, foram também entrevistados quatro coordenadores de alguns setores da organização, sendo um Coordenador de SGI (Sistema de Gestão Integrada), um Coordenador de PCP (Programação e Controle da Produção), um Coordenador de Projetos e um Coordenador do TRF (Troca Rápida de Ferramentas).

Ao ser questionado sobre os passos da implantação do Sistema Lean na empresa, o Coordenador de SGI relatou ter dado início à implantação no ano de 2013. Segundo ele, primeiramente, com o despertar do interesse do Sistema Lean no diretor da empresa, uma equipe definida por ele juntamente com a equipe de consultoria contratada, foi visitar uma indústria do ramo automotivo que já tinha o Lean como sistema produtivo a fim de observar seu funcionamento na prática. A consultoria contratada pela empresa fez uma pesquisa, primeiramente com o diretor e posteriormente com gestores, chamada de Pesquisa dos Sete Elementos com o objetivo de enxergar onde a empresa estava, onde ela queria chegar e se a perspectiva de crescimento dos funcionários era a mesma do diretor. Decidido implantar o sistema, a consultoria contratada realizou uma semana de eventos Lean. O primeiro Workshop da Visão Lean foi realizado com a intenção de apresentar o sistema e o programa Lean aos colaboradores. A primeira ferramenta a ser implantada foi o 5S. Para isso, foi realizado um Workshop 5S para gestores, onde foi definido gestores $5 \mathrm{~S}$ para cada departamento. Foi realizado em seguida um Workshop para Multiplicadores com o objetivo de treinar um grupo de funcionários. A partir deste Workshop, os funcionários foram treinados em grupos de mais ou menos 15 pessoas coordenadas por um gestor $5 \mathrm{~S}$ e dois multiplicadores. Depois dos treinamentos foi realizado um dia denominado como Dia do Sol na empresa, que consiste na prática da implantação do 5S. Nesse Dia do Sol todos os colaboradores dedicaram-se exclusivamente à implantação dos três primeiros Ss do $5 \mathrm{~S}$ (separar, organizar e limpar). Muita coisa foi retirada da empresa, o ambiente se tornou menos poluído de objetos e mais limpo e organizado. A ferramenta que foi implantada em seguida foi a de Troca Rápida de Ferramentas (TRF). Houve um Workshop TRF e sua implantação se deu pela redução dos sete desperdícios como um dos objetivos. A consultoria mudou o layout da fábrica para células e realizou uma semana Kaikaku, para a implantação desta ferramenta que consiste em um grupo de 9 a 15 pessoas que ficam estudando melhorias em uma célula produtiva no período de uma semana. O kaikaku consiste numa transformação radical de uma célula com a aplicação de todas as ferramentas Lean. Uma pré semanaKaikaku é feita, onde é filmado todo o processo da célula em estudo, a equipe assiste ao vídeo marcando os tempos de processos para identificar problemas. Foi realizado o Mapeamento do Fluxo de Valor, um mapeamento macro do estado atual para o estado desejado, com o objetivo de identificar onde estava o maior tempo de estoque. A consultoria nos acompanhou durante muito tempo com visitas mensais para orientações. Atualmente, a empresa segue com suas próprias pernas e outras ferramentas já foram implantadas. A última que implantamos no mês de março de 2016 é a de Gerenciamento Diário. 
Segundo o Coordenador de PCP, a fábrica foi rearranjada para possibilitar o trabalho em células com o objetivo de evitar desperdícios. No setor de PCP foi implantada a ferramenta Heijunka para nivelar a produção. A ferramenta TRF foi importante para possibilitar a fabricação de lotes menores e, consequentemente, aumentar a flexibilidade. Depois do trabalho da consultoria, a empresa continua com treinamentos internos, porém agora específicos para cada setor.

Durante o processo de implantação do novo sistema, algumas dificuldades foram notadas. Para o Coordenador de SGI, a maior dificuldade de implantação foi a cultura dos colaboradores da empresa que resistem a mudanças, fazer as pessoas entenderem que não se deve continuar produzindo defeitos, a partir do momento em que eles ocorrem. A rapidez com que o sistema começou a ser implantado na empresa, trouxe algumas dificuldades como a de seguir o cronograma inicial do projeto e a falta de preparação das pessoas para o início da implantação, onde as explicações sobre a implantação foram dadas de forma superficial e não mostrados os motivos detalhados das mudanças na empresa. Segundo o Coordenador de PCP a rejeição à mudança das pessoas, principalmente dos funcionários antigos, foi uma das principais dificuldades encontradas. É difícil fazer as pessoas entenderem as necessidades de cada coisa. Outra dificuldade foi a falta de colaboração da equipe de vendas da empresa, pois estavam acostumados a trabalhar com grandes estoques e isso era cômodo para eles. A falta de planejamento de programação para mudanças foi outra dificuldade, pois de início os pedidos foram atrasados devido à produção de lotes menores e, dessa forma, clientes passaram a reclamar pelos atrasos. Os clientes também começaram a reclamar da quantidade mínima dos lotes, pois antes com grandes estoques podia-se vender uma única caixa de produtos se o cliente quisesse. A empresa ainda tem dificuldade emdefinir o tamanho do lote mínimo ideal dos seus produtos. Na etapa atual percebe-se que a quantidade mínima de lotes que é produzida não é a ideal. Tem lote mínimo de 1000peças na cor cristal, 3000peças na cor branca e 5000peças coloridas. O Coordenador de Projetos acredita que o pessimismo das pessoas ao pensar que o novo sistema não daria certo e a resistência quando se fala em mudança, são pontos importantes em relação às dificuldades enfrentadas. A falta de conhecimento do sistema Lean de alguns funcionários também foi uma dificuldade já que muitos conheceram o sistema apenas na empresa. O Coordenador de TRF completa dizendo que o desafio é a mudança de hábitos e costumes. Muitas pessoas não são dispostas à mudança e resistem a elas. Outra grande dificuldade que a empresa enfrentou foi a falta de padrões, processos e produtos. Dessa forma tiveram que começar a padronizar os processos para depois aplicar o TRF e sentir melhorias.

Para o Coordenador de SGI, a ferramenta que apresenta maior dificuldade de implantação é o 5S, pois envolve disciplina por parte dos colaboradores. O Coordenador de PCP acredita que a ferramenta de maior dificuldade de implantação foi o TRF, pois até hoje não foi plenamente implantado. Aponta também a necessidade de priorizar a manutenção preventiva das máquinas já que antes só havia manutenção corretiva e o início da fabricação em lotes menores exigiu muito das máquinas, dessa forma elas começaram a quebrar. Já o Coordenador de Projetos acredita que, como a colaboração das pessoas é muito importante para a implantação das ferramentas, o $5 \mathrm{~S}$ tenha sido a ferramenta de maior dificuldade já que está diretamente relacionada com disciplina e organização dos funcionários. Para o Coordenador de TRF, que é mecânico 
responsável pelos moldes da linha, a ferramenta com maior dificuldade de implantação foi o TRF devido à cultura dos funcionários da linha.

No processo de implantação de uma nova sistemática de produção, muitas lições são aprendidas. O Coordenador de SGI aprendeu que a valorização dos funcionários é muito importante e que a preocupação em mostrar a eles os motivos das mudanças é essencial. O Coordenador de PCP aprendeu que deve-se preparar melhor para mudanças e entender as limitações do processo produtivo da empresa. Para o Coordenador de Projetos, a implantação do Sistema Lean era necessária para a empresa, pois com ela pode-se obter aprendizado e bons resultados. Segundo o Coordenador de TRF, para se ter bons resultados é preciso muita dedicação, pois é a própria mudança de hábitos que o sistema trouxe para a empresa que traz os benefícios.

Segundo os coordenadores entrevistados o Sistema Lean não foi plenamente implantado na empresa. Ainda existem problemas de cultura dos funcionários, faltam mais resultados do TRF, a conclusão do 5 S que está $75 \%$ concluído, falta a prática dos funcionários com a nova sistemática de produção, estabilizar o processo, adaptação de diversas ferramentas, manutenção preventiva, ferramentas multifuncionais para possibilitarem a TRF, falta engajamento das pessoas, funcionários abraçarem o novo sistema de produção, padronização, treinar o operador para que ela tenha autonomia sobre a máquina e garanta a qualidade do processo. Porém, todas as ferramentas já trouxeram resultados positivos para a empresa.

Há uma grande dificuldade de manutenção do Sistema Lean na empresa. Para os coordenadores entrevistados a empresa depende da disciplina, participação, aceitação e da realização das atividades das pessoas para que o sistema obtenha sucesso. A chegada de novos funcionários é outra dificuldade, pois a maioria não tem conhecimento do sistema. Outro fator que dificultou bastante a manutenção foi a troca do quadro de funcionários, gestores e coordenadores, algumas vezes, desde que o sistema foi implantado.

Foi feita ainda, entrevista com outros três funcionários, sendo um deles operador de produção e outros dois auxiliares de produção que serão nomeados neste trabalho como Operador de Produção, Auxiliar de Produção 01 e Auxiliar de Produção 02.

O Operador de Produção diz ter ficado ciente dos motivos da implantação do Sistema Lean na empresa em que trabalha. Por meio de workshops, ele observou que a mudança seria para melhoria geral da empresa como na organização, limpeza e padronização de produtos e processos.

Os Auxiliares de Produção 01 e 02 também afirmam estar cientes dos motivos da implantação do novo sistema através do Workshop para Multiplicadores realizado pela equipe de consultoria contratada pela empresa.

Os funcionários da organização receberam treinamentos para que uma nova forma de trabalhar fosse aplicada. O Operador de Produção participou do Workshplean e do treinamento de troca rápida de ferramentas (TRF) onde foi ensinado com detalhes as etapas da troca. Os Auxiliares de Produção 01 e 02 participaram do Workshop para Multiplicadores, do treinamento de TRF e de Kaikaku onde puderam aprender como trabalhar com padronização e entender que tudo pode ser melhorado. 
Para o Operador de Produção, a maior dificuldade durante a implantação do sistema Lean foi fazer com que todos os membros da equipe tivessem foco no mesmo objetivo, para isso houve muita insistência na realização correta das atividades. Segundo o Auxiliar de Produção 01 a maior dificuldade foia de aceitar os novos métodos de realização das atividades diárias, acreditar que as mudanças trariam resultados positivos para a empresa e aceitar a mudança de escala, pois os funcionários trabalhavam 6 dias e tinham 2 de folga e hoje trabalham 6 dias para apenas 1 dia de folga. Essa alteração de escala teve muita rejeição de funcionários e muitos pediram demissão. Já para o Auxiliar de Produção 02, a maior dificuldade foi aprender sobre o sistema Lean, pois não tinha conhecimento sobre o assunto, aceitar as novas formas de realização do trabalho e o pessimismo de achar que o novo sistema não daria certo.

Segundo o Operador de Produção, o sistema Lean trouxe melhorias como a padronização dos processos de troca de ferramentas que interfere diretamente na qualidade do produto final, a fixação do quadro de sombras que foi muito importante para a realização das tarefas dos operadores de produção, pois se tem as ferramentas à vista e disponíveis, a organização da bancada com os kits de ferramentas que vão entrar na linha e com os kits que saíram que facilitou o trabalho e reduziu o tempo de setup, e a colocação da rota que foi importante para a eliminação do acúmulo de produtos. Para o Auxiliar de Produção 01, a rota foi fundamental para a redução do acúmulo de caixas no meio do processo produtivo, foi obtido ganho de espaço no posto de trabalho, ganho de tempo, redução de desperdícios, padronização dos processos com a instalação da ficha de processo fixada na máquina, organização e limpeza do ambiente de trabalho. O Auxiliar de Produção 02 afirma que houve uma preocupação ergonômica. A altura da bancada fixada nas máquinas foi reduzida, o que deixou o produto ao alcance dos braços dos trabalhadores diminuindo o esforço físico, a iluminação melhorou, a colocação da esteira para o transporte de caixas foi importante, pois algumas caixas pesadas os funcionários tinham dificuldade de carregar. Aponta também que a colocação de máquinas em células possibilita que uma pessoa monitore mais de uma máquina ao mesmo tempo, e enfatiza também queestimulou o trabalho em equipe.

No ponto de vista do Operador de Produção, além dos colaboradores, os clientes também foram beneficiados. O tempo de entrega reduziu, houve redução de estoque, a produção passou a ser puxada de acordo com a necessidade dos clientes e os produtos estão mais flexíveis e com lotes menores, o que possibilita o interesse do comprador. Já para o Auxiliar de Produção 01, o aumento de vendas, o tempo de entrega menor, a competitividade no mercado, a produção puxada, a redução de estoque, a organização, a ergonomia, e a redução dos sete desperdícios foram os principais benefícios da organização. O Auxiliar de Produção 02 acredita que os maiores benefícios estão na instalação de um sensor pokayoke na máquina, que avisa quando o pigmento está acabando e precisa ser reabastecida, na redução do tamanho da bancada do posto de trabalho que possibilita o alcance dos produtos e, consequentemente, menos fadiga dos trabalhadores, na redução de máquinas ociosas, na redução do tempo de setup devido à aplicação do TRF, no aumento de vendas, na garantia da competitividade no mercado, na flexibilidade de produtos e na satisfação dos clientes com tempo de entrega menores. 
Pelas entrevistas pode-se inferir que a implantação de um sistema novo na organização requer tempo de adaptação dos funcionários da mesma. O Operador de Produção relata que no início foi bastante difícil, os primeiros 6 meses foram de aprendizado e aceitação. Hoje muitos dos funcionários já sabem como realizar suas atividades e que devem seguir padrões. Para o Auxiliar de Produção 01, leva cerca de 5 meses para uma boa aceitação das mudanças. Conforme as técnicas e ferramentas foram sendo implantadas e foram dando bons resultados não só para a empresa, mas para a realização das atividades dos colaboradores, que os mesmos perceberam quão bom o sistema seria e que estava dando certo. Antes os funcionários ficavam perdidos entre inúmeras caixas no meio do processo, as bancadas encostavam-se na costela que no final do turno já estava machucada, os auxiliares de produção tinham que abrir e preparar as caixas para embalar os produtos. Hoje, o $5 \mathrm{~S}$ possibilitou organização da linha, limpeza do local de trabalho, boa gestão visual, e a rota faz a preparação das caixas para que os auxiliares de produção apenas coloquem os produtos, depois passam retirando o que foi produzido e nada fica acumulado. Já para o Auxiliar de Produção 02, os primeiros 5 meses foram mais difíceis de se adaptar, sendo muitas as mudanças. Porém, os colaboradores ainda estão se adaptando, pois todo dia tem algo novo para ser aprendido.

\section{DISCUSSÕES}

O objetivo geral deste trabalho que consiste em analisar as possibilidades, os recursos necessários, as dificuldades e benefícios da utilização de técnicas e ferramentas do Sistema Toyota de Produção em uma indústria de embalagens plásticas da região de Marília - SP foi alcançado por meio do estudo de caso com coleta de dados a partir de entrevistas com os colaboradores da empresa em estudo.

Os objetivos específicos permitiram revelar as principais dificuldades encontradas na implantação do sistema proposto, bem como delinear a percepção dos gestores e dos colaboradores sobre a nova metodologia de trabalho. Os motivos que levaram a empresa em estudo a adotar as ferramentas do Sistema Toyota de Produção foram, principalmente, a necessidade de redução de estoques, desperdícios e custos. As principais ferramentas utilizadas são o $5 \mathrm{~S}$, o Kaikaku, a troca rápida de ferramenta, relatório A3, o planejamento HoshinKanri, mapeamento do fluxo de valor, padronização de trabalho e gestão diária, sendo que as que trouxeram maior resultados foram o planejamento HoshinKanri, gestão diária e relatório A3. Houve investimento para a implantação do sistema basicamente em máquinas e equipamentos, consultoria e treinamentos e, principalmente, em mão de obra. A principal dificuldade de implantação foi a mudança de cultura dos funcionários, que dificultou bastante este processo. Os resultados da aplicação do sistema são satisfatórios para a empresa, possibilitaram melhorias e indicadores mais precisos, como a redução do lead time, estoque e setup. 


\section{CONCLUSÕES}

O Sistema Toyota de Produção foi desenvolvido por TaiichiOhno em consequência das necessidades da Toyota. Tem como principal objetivo a eliminação de desperdícios a fim de aumentar a produtividade de um processo produtivo com a aplicação de ferramentas desenvolvidas por essa sistemática de produção.

Segundo o referencial teórico abordado nesse trabalho (JUNIOR, 2008), um programa Kaizen bem planejado é fracionado em três segmentos: orientado para a administração, orientado para o grupo e orientado para a pessoa. No segmento orientado para o grupo o objetivo é desenvolver métodos, análises e processos de resolução de problemas na empresa, identificando sempre sua causa raiz e implantando as soluções encontradas envolvendo ferramentas de gestão e análise da qualidade e atentando para as necessidades de melhoria. Já o segmento orientado para a pessoa propõe desencadear ações de melhorias para os colaboradores da organização objetivando a satisfação do mesmo em relação ao seu local de trabalho, segurança pessoal e tudo aquilo que possa auxiliar para o conforto, confiança e melhor desempenho dos funcionários na organização, sendo que essa percepção dos colaboradores foi percebida no estudo de caso. Contudo, é necessário enfatizar que a relutância das pessoas às mudanças é um dos principais obstáculos para a implantação do sistema e, portanto, é necessário investimento e disponibilidade de tempo para o esclarecimento dos colaboradores e o convencimento para a sua aderência ao sistema.

Pode-se concluir que a implantação do Sistema Toyota de Produção na indústria em estudo foi de suma importância para seus processos produtivos tornando possível a otimização da produção na fabricação de lotes menores com qualidade, menor custo, redução de estoques e desperdícios através da aplicação de ferramentas do sistema. 


\title{
Analysis of the Toyota System in a Plastic Packaging Industry of the Marília Region - SP
}

\begin{abstract}
Production systems have evolved significantly, through the handmade, fordist toyotist. Currently many companies use the Toyota Production System, whose main focus eliminate any waste that do not add value to production to increase productivity and ensure the overall quality of its products. As techniques and tools of this system can be cited Just in Time, which is the proposal to produce goods and services at the time they are needed to meet the needs of its customers, Autonomation that aims to empower the employee whenever necessary and Kaizen that focuses on continuous improvement of production process and others. This work aims to analyze the implementation of the Toyota Production System in a plastic packaging industry Marilia-SP region in order to analyze the positive and negative impacts suffered by the company in implementing this system. The research methods used were exploratory research with survey articles and relevant authors of the area and reading material, and case studies through interviews in the company under study. This work had as its main results to optimize the production quality, cost reduction, inventory reduction, and reduced waste by applying the Toyota Production System tools.
\end{abstract}

KEYWORDS: Toyota production system. Plastic packaging industry. Lean manufacturing. 


\section{REFERÊNCIAS}

DENNIS, Pascal. Produção Lean Simplificada. 2. ed. Porto Alegre: Bookman, 2008.

FUSCO, José P. A.; SACOMANO, José B. Operações e Gestão Estratégica da Produção. São Paulo: Arte \& Ciência, 2007.

GHINATO, Paulo. Sistema Toyota de Produção: Mais do Que Simplesmente Justin-Time. Revista Produção, São Paulo, v. 5, n. 2, p.169-189, 1995.

GIL, Carlos Antônio. Como Elaborar Projetos de Pesquisa. 3. ed. São Paulo: Atlas, 1996.

JACOBS, Robert F.; CHASE, Richard B. Administração da Produção e de Operações: O Essencial. 1 ed. Porto Alegre: Bookman, 2009.

JUNIOR, Eudes L. C. Gestão do Processo Produtivo. 20.ed. Curitiba: IBPEX, 2008.

LIKER, J. K.; MEIER, D. O Modelo Toyota - Manual de Aplicação: Um Guia Prático Para a Implementação dos 4 Ps da Toyota. Porto Alegre: Bookman, 2007.

LIKER, Jeffrey K.; CONVIS, Gary L. O Modelo Toyota de Liderança Lean: Como Conquistar e Manter a Excelência pelo Desenvolvimento de Lideranças. Porto Alegre: Bookman, 2013.

MONDEN, Yasuhiro. Sistema Toyota de Produção: Uma Abordagem Integrada ao Just - in - Time. 4. ed. Porto Alegre: Bookman, 2015.

MUNIZ, Jorge J. et al. Administração de Produção. Curitiba: IESDE Brasil S.A., 2012.

NETO, Diógenes L. Negócios Estratégicos. BRASILADMIN, 2007.

OHNO, Taiichi. O Sistema Toyota de Produção. Reimp. 2013. Porto Alegre: Bookman, 1997.

OSONO, E.; SHIMIZU, N.; DORTON, J. K.; TAKEUSHI, H. (2008), O Relatorio Toyota, Rio de Janeiro: Ediouro. 
PARANHOS FILHO, Moacyr. Gestão da Produção Industrial. 20. ed. Curitiba: Ibpex, 2007.

RODRIGUES, Marcos V. Entendendo, Aprendendo e Desenvolvendo Sistemas de Produção Lean Manufacturing. Rio de Janeiro: Elsevier, 2014.

ROMEIRO FILHO, E.; FERREIRA, C. V.; CAUCHICK MIGUEL, P. A.; GOUVINHAS, R. P.; NAVEIRO, R. M. Projeto do Produto. Rio de Janeiro: Elsevier, 2011.

SHINGO, S.: O Sistema Toyota de Produção do Ponto de Vista da Engenharia de Produção. 2. ed, Porto Alegre: Bookman, 1996.

SLACK, Nigel; JOHNSTON, Robert; CHAMBERS, Stuart. Administração da Produção. 3. ed. São Paulo: Atlas, 2009.

WERKEMA, Cristina. Lean Seis Sigma: Introdução as Ferramentas do Lean Manufacturing. 2. ed. Rio de Janeiro: Campus, 2012.

WOMACK, James P.; JONES, Daniel T. A Mentalidade Enxuta nas Empresas: elimine o desperdício e crie riquezas. Rio de Janeiro: Campus, 1998.

WOMACK, James P.; JONES, Daniel T.; ROOS, Daniel. A Máquina que Mudou o Mundo. 18. ed. Rio de Janeiro: Elsevier, 2004.

WOOD JÚNIOR, Thomaz. Fordismo Toyotismo e Volvismo: Os caminhos da indústria em busca do tempo perdido. Revista de Administração de Empresas, São Paulo, v. 32, n. 4, p. 6-18, set./out. 1992.

YIN, Robert K., Estudo de Caso: Planejamento e Métodos. 4. ed. Porto Alegre: Bookman, 2010. 
Recebido: 22 nov. 2016

Aprovado: 14 fev. 2017

DOI: 10.3895/gi.v13n1.5061

Como citar:

DETREGIACHI FILHO, E.; MARTINS, N. O.; HERRERA, V. E. Análise do Sistema Toyota em uma indústria de embalagens plásticas da região de Marília - SP. R. Gest. Industr., Ponta Grossa, v. 13, n. 1, p. 75-98, jan./mar. 2017. Disponível em: <https://periodicos.utfpr.edu.br/rgi>. Acesso em: XXX.

Correspondência:

Edson Detregiachi Filho

Av. Higino Muzzi Filho, 529, CEP: 17.525-901, Marília, SP, Brasil.

Direito autoral: Este artigo está licenciado sob os termos da Licença Creative Commons-Atribuição 4.0 Internacional.

(c) (1) 